\title{
Perancangan Sistem Persediaan Berbasis Website pada PT. Asahi Fibreglass
}

\section{Web-Based Inventory System Design at PT. Asahi Fibreglass}

\author{
Ignatius Adrian Mastan ${ }^{1}$, Raynaldo Kurniawan ${ }^{1^{*}}$ \\ ${ }^{1}$ Program Studi Sistem Informasi, Universitas Bunda Mulia, Jl. Lodan Raya No. 2 Ancol, Jakarta Utara 14430, \\ Indonesia
}

Diterima: 5 Mei, 2020 / Disetujui: 1 Juli, 2020

\begin{abstract}
The development of technology which continues to increase rapidly has an impact on the internal processing of a company that is required to run faster. Information system technology is the main solution as a tool for activities in a company that is faster and more practical, and allows obtaining data that is more valid, precise and minimizes errors. PT Asahi Fibreglass is a company in Jakarta which started its business from 2001 which is engaged in manufacturing and marketing products for the needs of fiberglass products for industrial, residential, building and property needs. In operational activities of PT. Asahi Fibreglass has several obstacles in the process of recording stock items which still use a book-based recording method which makes recording look messy, there are differences in recording the physical stock of goods in the warehouse with the recording of goods recorded in a Microsoft Excel file, there are missing or tucked data because it still uses manual methods and is still bookbased. The purpose of creating a web-based inventory information system at PT Asahi Fibreglass is a system improvement in regulating the flow or path of the process of in and out of warehouse goods that will replace the old inventory system that still uses Microsoft Excel, as well as speed up the process of making reports, and minimize errors in the inventory recording process.
\end{abstract}

Keywords: Inventory, Information system, Website

\begin{abstract}
ABSTRAK
Perkembangan teknologi yang terus meningkat secara pesat telah berdampak pada pemrosesan proses internal di suatu perusahaan dituntut untuk berjalan lebih cepat. Teknologi sistem informasi menjadi solusi utama sebagai alat bantu dalam aktivitas di suatu perusahaan semakin cepat dan praktis, dan memungkinkan mendapatkan datadata yang lebih valid, tepat dan meminimalkan adanya kesalahan-kesalahan. PT Asahi Fibreglass merupakan sebuah perusahaan di Jakarta yang memulai usahanya dari 2001 yang bergerak di dalam bidang manufaktur dan pemasaran produk untuk keperluan bidang produk fiberglass untuk keperluan bidang industri, perumahan, serta kontraktor bangunan, dan properti. Dalam kegiatan operasional PT Asahi Fibreglass memiliki beberapa kendala dalam proses pencatatan stok barang yang masih menggunakan cara pencatatan book-based yang menjadikan pencatatan terlihat tidak rapih, terdapat perbedaan pencatatan pada stok fisik barang di gudang dengan pencatatan barang yang dicatat di dalam file Microsoft Excel, adanya data yang hilang atau terselip karena masih menggunakan cara yang manual dan masih menggunakan book-based. Tujuan dibuatnya sistem informasi persediaan berbasis web pada PT. Asahi Fibreglass ini merupakan perbaikan sistem dalam mengatur flow atau jalur dari proses keluar masuk barang gudang yang akan menggantikan sistem persediaan yang lama yang masih menggunakan Microsoft Excel, serta mempercepat proses pembuatan report, serta memperkecil adanya kesalahan pada proses pencatatan persediaan.
\end{abstract}

Kata Kunci: Persediaan, Sistem informasi, Website

\section{PENDAHULUAN}

Salah satu indikator yang memperlihatkan kualitas kinerja adalah kualitas pelayanan
(Rowena, Wilujeng dan Rembulan, 2020). Gap antara tingkat kepentingan dan tingkat harapan mengindikasikan konsumen menginginkan

*email: kurniawanreynaldo211@gmail.com 
kualitas pelayanan yang lebih dibandingkan dengan yang diterima saat ini (Wilujeng dan Rembulan, 2019; Wilujeng et al., 2019) Pengukuran tingkat kepuasan terhadap kinerja perusahaan dan besarnya pemahaman terhadap pelanggan (Wilujeng, Rembulan dan Regina, 2019) dapat dilakukan untuk meminimalkan kesalahan.

Pada perkembangan teknologi yang terus maju secara pesat dari waktu ke waktu yang membuat proses di suatu perusahaan dapat diselesaikan secara cepat. Teknologi sistem informasi menjadi solusi utama sebagai alat bantu dalam aktivitas di suatu perusahaan semakin cepat dan praktis, dan memungkinkan mendapatkan data-data yang lebih valid, tepat dan meminimalkan adanya kesalahankesalahan. Pada kenyataannya sistem informasi sudah banyak digunakan pada perusahaanperusahaan yang berkembang dan maju, baik dengan menggunakan berbagai bahasa pemograman yang ada yang sesuai dengan perusahaan pengguna sistem informasi tersebut. Sistem informasi pun pada zaman ini banyak digunakan dalam segala bidang dengan menggunakan program ataupun sistem yang memiliki banyak platform, antara lain desktop maupun website.

Setiap platform sistem informasi memiliki kelebihan dan kekurangan masihmasing, kedua platform tersebut memiliki fungsi-fungsi yang meningkatkan produktivitas bagi perusahaan yang menggunakannya, dan penggunaan website sebagai platformnya dapat membuat perusahaan lebih cepat dalam pembagian datanya karena bersifat daring. Pada suatu sistem website persediaan menggunakan banyak kegunaan seperti menyimpan data-data barang yang masuk dan keluar, permintaan konsumen, ketersediaan barang yang ada di gudang, dan menampilkan report dari stok perusahaan. Salah satu perusahaan yang membutuhkan sistem informasi persediaan adalah PT. Asahi Fibreglass.

Industri manufaktur perlu melakukan manajemen persediaan karena dapat menimbulkan biaya yang tinggi (Karo-Karo, Lois dan Nurprihatin, 2017). PT. Asahi Fibreglass merupakan sebuah perusahaan di Jakarta yang memulai usahanya dari 2001 yang bergerak di dalam bidang manufaktur dan pemasaran produk untuk keperluan bidang produk fiberglass untuk keperluan bidang industri, perumahan, serta kontraktor bangunan, dan properti. Di dalam perusahaan ini terkadang terjadi kendala dalam proses pencatatan stok barang yang masih menggunakan cara pencatatan book-based yang menjadikan pencatatan terlihat tidak rapih, terdapat perbedaan pencatatan pada stok fisik dan pencatatan di dalam Microsoft Excel, adanya data yang hilang atau terselip karena masih menggunakan cara yang manual dan masih menggunakan book-based. Dengan adanya bantuan sistem informasi kesalahan-kesalahan seperti ini dapat diminimalisasi agar tidak sering terjadi,yang membuat perusahaan menjadi lebih lancar lagi dalam proses bisnisnya.

Penelitian sebelumnya menyelesaikan permasalahan persediaan dengan melakukan rekayasa pada jumlah pemesanaan (lot sizing) ke pemasok (Karo-Karo, Lois dan Nurprihatin, 2017). Permasalahan persediaan juga dibahas untuk meminimalkan pemborosan dengan lean manufacturing (Karo-Karo, Lois dan Nurprihatin, 2017). Integrasi metode lean six sigma dan line balancing digunakan untuk meminimalkan pemborosan proses produksi dan waktu menunggu (Nurprihatin, Yulita dan Caesaron, 2017; Tannady et al., 2019; Regina, Luin dan Rembulan, 2020) Stok yang terbatas membuat penelitian terdahulu membahas tentang pemenuhan permintaan dengan optimalisasi jaringan distribusi (Rembulan et al., 2020). Permasalahan persediaan tidak hanya karena kekurangan stok, namun juga bisa disebabkan oleh kelebihan stok. Kasus kelebihan stok ditangani dengan merekayasa strategi distribusi (Nurprihatin et al., 2019). Penelitian terdahulu menyarankan agar bisnis yang berkembang dapat membuat sistem atau aplikasi yang terintegrasi dengan database (Rembulan, 2018).

Penelitian ini akan menghasilkan sebuah sistem informasi persediaan yang akan digunakan oleh perusahaan dengan harapan dapat menyelesaikan masalah pada perusahaan tersebut dan dapat memperlancar atau membuat proses pengecekan persediaan berjalan lebih efisien dan akurat.

\section{TINJAUAN PUSTAKA}

\subsection{Persediaan (Inventory)}

Perusahaan harus memelihara empat jenis persediaan yaitu (Heizer, Render dan Munson, 2017):

1. Persediaan bahan mentah.

2. Persediaan barang dalam proses. 
3. Persediaan Maintenance/Repair/Operating (MRO).

4. Persediaan barang.

Persediaan adalah bahan baku dan penolong, barang jadi dan barang dalam produksi dan barang-barang yang tersedia, yang dimiliki dalam perjalanan dalam tempat penyimpanan atau konsinyasikan kepada pihak lain pada akhir periode (Kotler dan Keller, 2016).

\subsection{Flow Chart}

Flow chart merupakan penggambaran secara grafik dari langkah-langkah dan urutan prosedur suatu program, biasanya mempengaruhi penyelesaian masalah yang khusunya perlu dipelajari dan dievaluasi lebih lanjut (Indrajani, 2011). Flow chart dibedakan menjadi 5 jenis, antara lain flow chart sistem, document flow chart, schematic flow chart, flow chart program, dan process flow chart.

\section{METODOLOGI}

Waterfall atau biasa disebut classic life cycle merupakan model klasik yang bersifat sistematis, berurutan dalam membangun sebuah perangkat lunak (Pressman dan Maxim, 2015). Beberapa tahapan dalam metode pengembangan waterfall pada Gambar 1 adalah sebagai berikut (Pressman dan Maxim, 2015):

\section{Communication}

Pada tahap ini akan dilakukan inisiasi proyek, seperti menganalisis masalah yang ada dan tujuan yang akan dicapai. Selain itu dilakukan juga requirements gathering, dimana akan dikumpulkan requirement dari user melalui analisis kuesioner.

\section{Planning}

Tahap ini merupakan tahap dimana akan dilakukan estimasi mengenai kebutuhankebutuhan yang diperlukan untuk membuat sebuah sistem. Selain itu, penjadwalan dalam proses pengerjaan juga ditentukan pada tahap ini.

3. Modeling

Kemudian mulai masuk pada tahap perancangan dimana perancang menerjemahkan kebutuhan sistem kedalam representasi untuk menilai kualitas sebelum tahap selanjutnya dikerjakan. Tahap ini lebih difokuskan pada atribut program, seperti struktur data, arsitektur perangkat lunak, dan detail prosedur.

4. Construction

Construction merupakan proses membuat kode. Coding atau pembuatan kode merupakan penerjemah desain dalam bahasa yang bisa dikenali oleh komputer. Programmer akan menerjemahkan transaksi yang diminta oleh user. Tahap ini yang merupakan tahapan secara nyata dalam mengerjakan suatu perangkat lunak, artinya penggunaan komputer akan dimaksimalkan dalam tahapan ini. Setelah pembuatan kode selesai maka akan dilakukan testing terhadap sistem yang telah dibuat tadi. Tujuan testing adalah menemukan kesalahan-kesalahan terhadap sistem tersebut untuk kemudian bisa diperbaiki.

5. Deployment

Tahap ini bisa dikatakan final dalam pembuatan sebuah perangkat lunak atau sistem. Setelah melakukan analisis, desain dan pembuatan kode maka sistem yang sudah jadi akan digunakan oleh user. Kemudian perangkat lunak yang telah dibuat harus dilakukan pemeliharaan secara berkala.

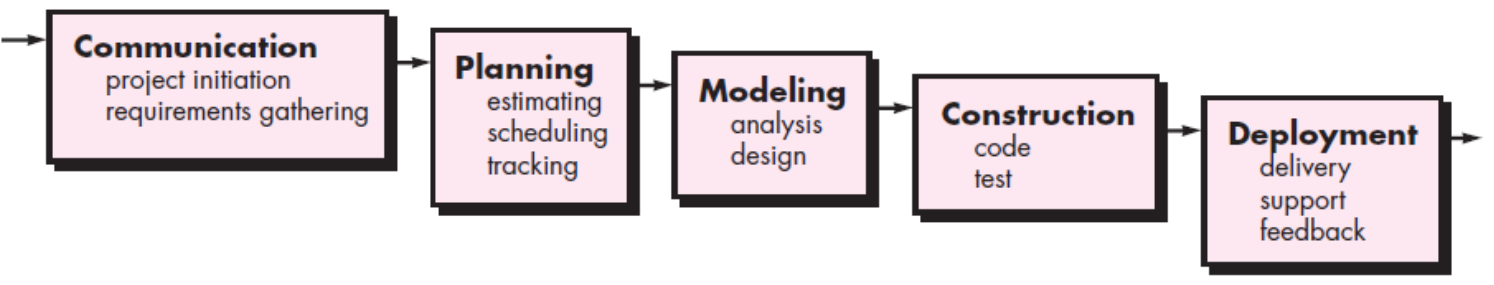

Gambar 1. Model Waterfall 


\section{HASIL DAN PEMBAHASAN}

Berikut ini adalah hasil analisis dari pembuatan sistem persediaan pada perusahaan.

\subsection{Analisis Sistem Berjalan}

Setelah melakukan analisis pada perusahaan, dapat diketahui sistem yang sudah berjalan ini kurang efektif, karena proses pencatatan data untuk pengolahan datanya menggunakan Microsoft Excel yang membuat prosesnya kurang cepat. Analisis sistem yang sedang berjalan menguraikan secara sistematis aktivitas-aktivitas yang terjadi dalam proses pencatatan persediaan stok barang pada perusahaan. Agar proses pembangunan sistem dapat berjalan dengan baik, dan lancar, maka lebih jelas permodelannya menggunakan flow chart sistem.

Proses diawali pada saat supplier melakukan pengiriman bahan baku disertai dengan surat jalan bahan dari supplier. Setelah itu admin gudang melakukan proses pengecekan terhadap barang dengan surat jalan, apakah sudah sesuai atau belum, jika tidak sesuai barang akan dikembalikan kepada pihak supplier, jika barang sesuai admin gudang akan melaporkan data barang masuk beserta surat jalannya kepada kepala gudang, dan akan dibuatkan surat barang masuk oleh kepala gudang. Proses selanjutnya adalah proses produksi, Bagian kantor mendapatkan order pesanan dari sales, yang kemudian bagian kantor melaukan cek terhadap stok barang yang dipesan, apakah barang tersebut sudah siap atau belum,jika sudah siap kantor akan melakukan penjadwalan untuk pengiriman barang. Jika belum maka akan dibuatkan Surat Perintah Kerja (SPK) kepada kepala gudang, lalu kepala gudang akan memberikan perintah untuk melakukan produksi terhadap bagian produksi berdasarkan SPK yang di dapat dari bagian kantor, Setelah bagian produksi selesai melakukan proses produksi, admin gudang akan mengecek keadaan barang dan melaporkannya kepada kepala gudang,dan dicatat pada catatan produksi harian, yang akan dibuatkan laporan produksi harian.

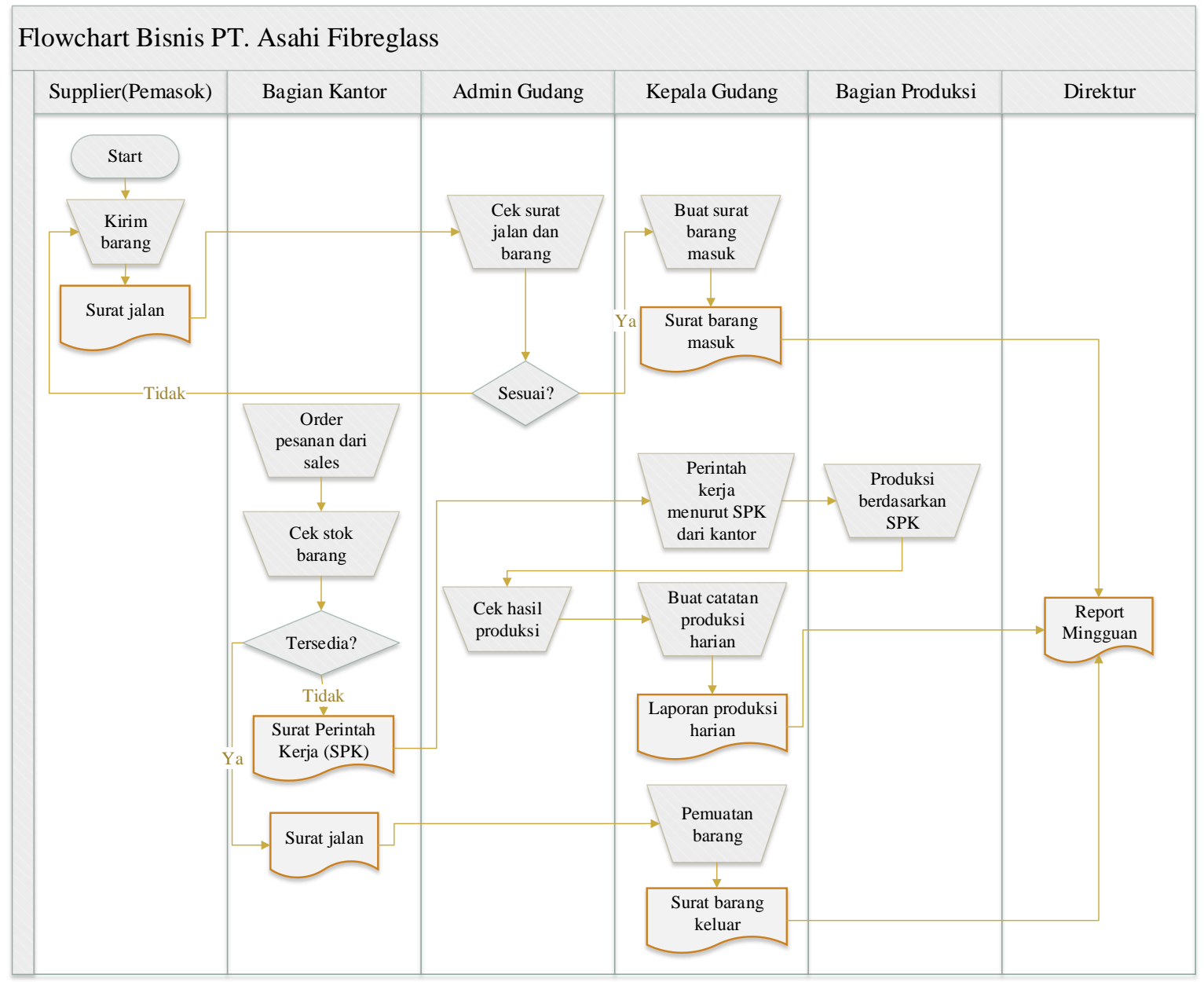

Gambar 2. Flow Chart Proses Bisnis 
Tabel 1. Tabel Identifikasi Masalah

\begin{tabular}{llll}
\hline \multicolumn{1}{c}{ Masalah } & \multicolumn{1}{c}{ Penyebab Masalah } & Titik Keputusan \\
\hline $\begin{array}{l}\text { Pengolahan data stok barang yang } \\
\text { masih dilakukan secara manual. }\end{array}$ & $\begin{array}{l}\text { Terkadang terjadi selisih perhitungan barang dan } \\
\text { informasi stok barang yang diberikan terkadang }\end{array}$ & Proses stok barang. \\
tidak sesuai dengan stok riilnya. & & & \\
Pengelolahan data persediaan & Terjadinya penumpukan berkas dan untuk & Proses & pengolahan \\
barang masih dicatat secara & pencarian data yang diperlukan memakan waktu & data & persediaan \\
manual. & yang lama. & barang. & \\
Kesulitan dalam pencatatan dan & Terkadang terjadi kesalahan dalam pencatatan & Proses & pencatatan \\
pembuatan laporan barang masuk & dan pembuatan laporan karena banyaknya barang & dan & pembuatan \\
dan keluar. & yang masuk dan keluar. & laporan. & \\
\hline
\end{tabular}

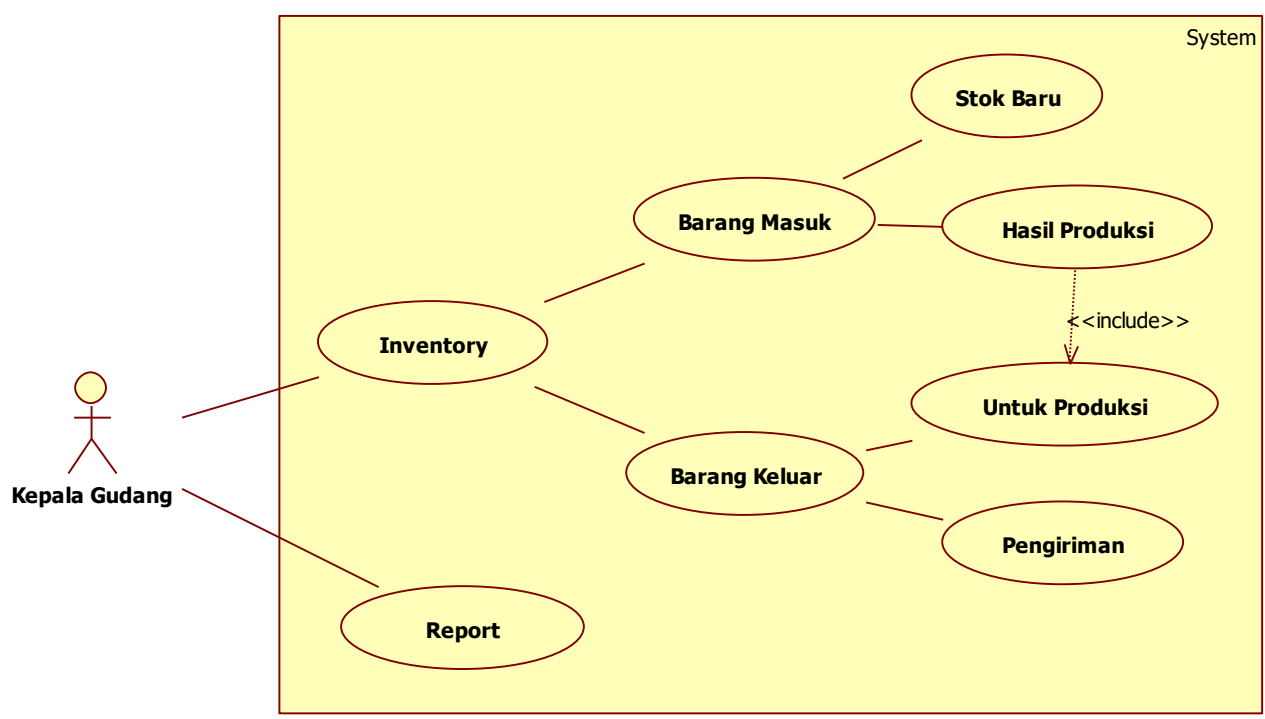

Gambar 3. Use Case Diagram Sistem Infromasi Persediaan

Pada proses selanjutnya merupakan proses pengiriman barang, proses diawali dari bagian kantor yang mendapatkan order dari sales, lalu melakukan pengecekan ketersediaan barang, jika barang yang disorder ada di dalam stok, maka bagian kantor akan melakukan penjadwalan pengiriman, lalu akan dibuatkan surat jalan yang akan dikirimkan kepada kepala gudang, lalu kepala gudang akan melakukan pemuatan barang dan membuat surat barang keluar. Proses yang terakhir merupakan proses report mingguan terhadap direktur, ada tiga report dalam report mingguan, yaitu: report barang masuk, report produksi harian, report barang keluar.

\subsection{Identifikasi Masalah}

Berdasarkan dari hasil observasi yang sudah dilakukan, peneliti dapat menarik beberapa identifikasi masalah yang ada di dalam sistem perusahaan yang lama, beberapa permasalahannya seperti yang ditampilkan Tabel 1. 


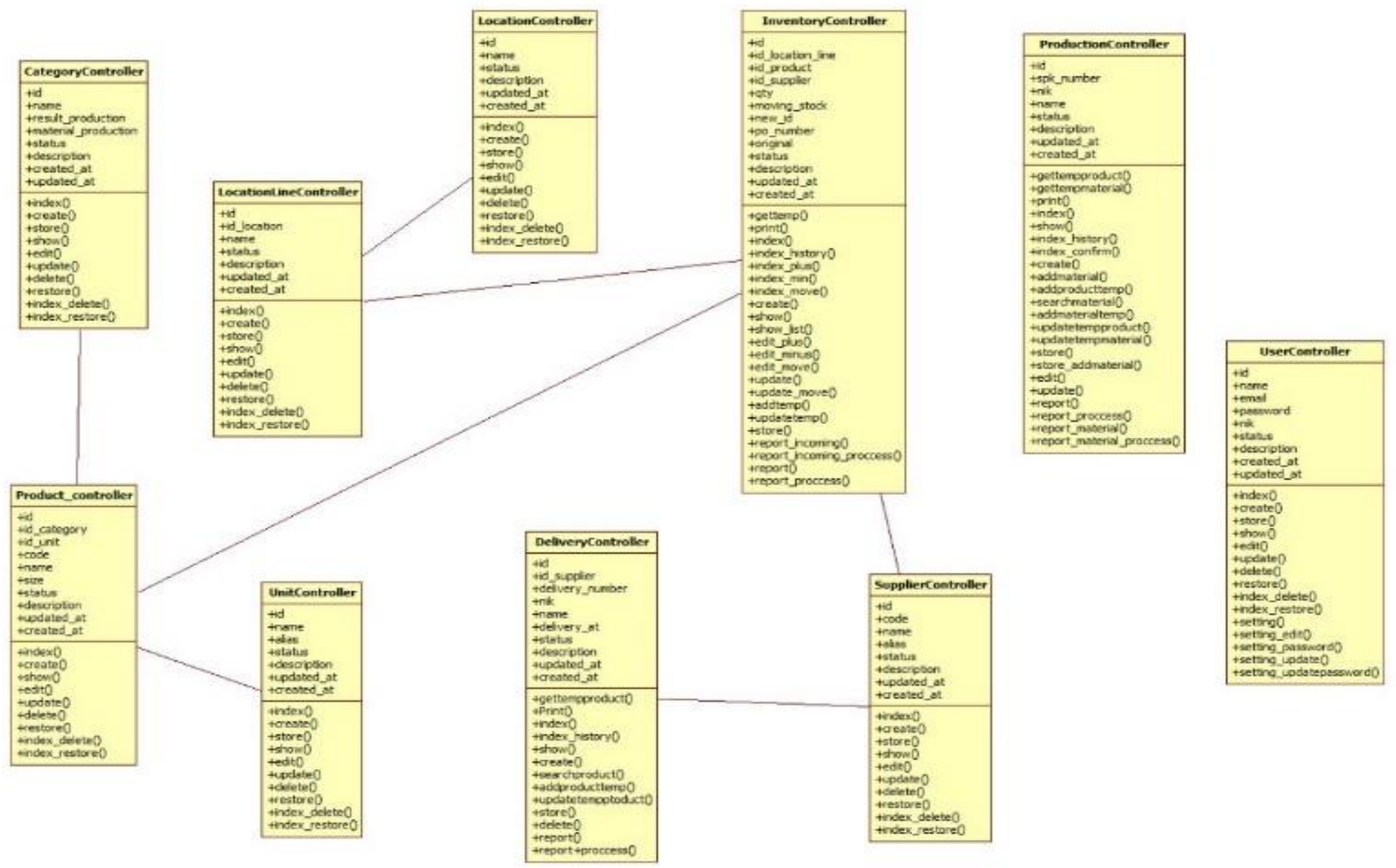

Gambar 4. Class Diagram Sistem Informasi Persediaan 


\subsection{Perancangan Desain Sistem}

Pada perancangan kali ini penulis menggunakan $U M L$ dalam melakukan desain sistem informasi pada perusahaan sebagai berikut:

\section{Use case diagram}

Pada Gambar 3 terdapat 1 aktor yaitu kepala gudang. Aktor kepala gudang dapat melakukan beberapa interaksi dengan sistem, interaksi dengan sistem berupa menu inventory yang mencakup barang masuk dan barang keluar. Isi dari barang masuk ada penambahan stok baru yang berfungsi untuk menambah data barang material yang digunakan untuk keperluan proses produksi, kemudian fungsi hasil produksi adalah mencatat data barang hasil produksi yang sudah diproduksi perharinya. Kemudian isi dari barang keluar merupakan pencatatan data barang yang keluar untuk produksi dan untuk pengiriman, Untuk produksi data barang yang diambil merupakan data barang material setengah jadi sebagai bahan bakunya, kemudian ada juga pengiriman yang merupakan pencatatan untuk data-data pengiriman barang hasil produksi kepada pelanggan. Dan yang terakhir kepala gudang dapat menggunakan fungsi report sebagai rangkuman dari aktivitas di dalam sistem yang dapat dicetak ke dalam bentuk laporan yang dapat digunakan untuk melakukan pengecekan berkala.

2. Class diagram

Pada perancangan sistem persediaan terdapat 10 (sepuluh) class, yang terdiri dari :

a. Class category controller

Class category controller berfungsi untuk melakukan transaksi perihal category. Transaksi yang dilakukan berupa penambahan dan penghapusan data category, berdasarkan data category yang akan digunakan untuk membedakan produk.

b. Class product controller

Class product controller berfungsi untuk melakukan transaksi perihal product. Transaksi yang dilakukan berupa penambahan dan penghapusan data product, berdasarkan data category yang akan digunakan untuk pendataan barang yang ada.

c. Class unit controller

Class Unit controller berfungsi untuk melakukan transaksi perihal unit.
Transaksi yang dilakukan berupa penambahan data unit, berdasarkan data unit yang akan digunakan untuk jumlah satuan barang.

d. Class location line controller

Class location line controller berfungsi untuk melakukan transaksi perihal location line. Transaksi yang dilakukan berupa penambahan dan penghapusan data location line, berdasarkan data location line yang akan digunakan untuk pengaturan tata letak barang di dalam gudang.

e. Class location controller

Class location controller berfungsi untuk melakukan transaksi perihal location. Transaksi yang dilakukan berupa penambahan dan penghapusan data location, berdasarkan data location yang akan digunakan untuk pengaturan penataan gudang yang ada.

f. Class delivery controller

Class delivery controller berfungsi untuk melakukan transaksi perihal delivery. Transaksi yang dilakukan berupa penambahan dan penghapusan data delivery, berdasarkan data delivery yang akan digunakan untuk pendataan pengiriman.

g. Class inventory controller

Class inventory controller berfungsi untuk melakukan transaksi perihal persediaan. Transaksi yang dilakukan berupa penambahan dan penghapusan data persediaan, berdasarkan data persediaan yang akan digunakan untuk pengecekan stok barang.

h. Class supplier controller

Class supplier controller berfungsi untuk melakukan transaksi perihal supplier. Transaksi yang dilakukan berupa penambahan dan penghapusan data supplier, berdasarkan data supplier yang akan digunakan untuk pendataan supplier yang melakukan kerja sama.

i. Class production controller

Class production controller berfungsi untuk melakukan transaksi perihal production. Transaksi yang dilakukan berupa penambahan dan penghapusan data production, berdasarkan data production yang akan digunakan untuk pendataan produksi barang yang terjadi. 
j. Class user controller

Class user controller berfungsi untuk melakukan transaksi perihal user. Transaksi yang dilakukan berupa penambahan dan penghapusan user.

\subsection{Desain Website Sistem Persediaan}

Pada halaman sistem persediaan perusahaan ini adalah halaman welcome dimana halaman ini adalah untuk melakukan $\log$ in ataupun registrasi jika belum memiliki account.

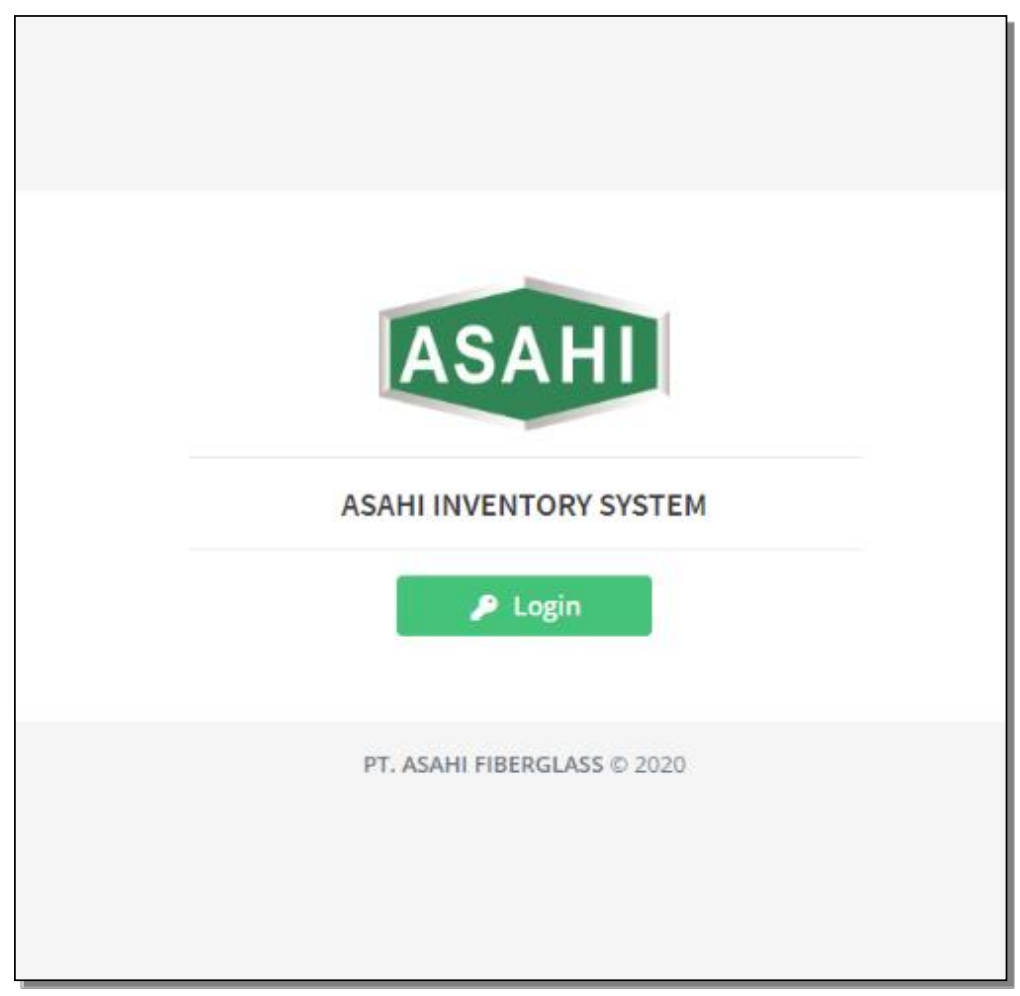

Gambar 5. Halaman Login

\section{ASAH] Inventory System}

E Master Dara * un irsentory * a Report

INVENTORY - NEW STOCK

NEW STOCK

1. Add item

Item (Size) - Category

BA-06 (BA Series) - Barang Jadi

Location - Line

Gudang 2 - Line 1

Qty 
E Master Dara * in Inventory * a Report

REPORT - REPORT INVENTORY

REPORT INVENTORY

Location - Location Line

All

Date

$\mathrm{dd} / \mathrm{mm} / \mathrm{W} / \mathrm{y}$

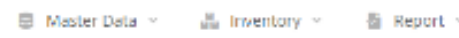

REPORT - REPORT PRODUCTION

REPORT PRODUCTION

Product Name

All

From Date

$\mathrm{dd} / \mathrm{mm} / \mathrm{ym} /$

To Date

$\mathrm{dd} / \mathrm{mm} / \mathrm{m} / \mathrm{m}$

Gambar 8. Halaman Report Production

Gambar 6 menjelaskan halaman new stock adalah halaman yang berfungsi untuk mencatat data barang masuk yang terjadi perharinya dan memiliki 3 bagian dalam proses pendataannya, yaitu: add item, list item, dan detail stock.

Gambar 7 merupakan halaman yang berfungsi untuk membuat report tentang stok barang yang ada didalam sistem, dan dapat dipilih tanggal yang diinginkan untuk reportnya.

Gambar 8 adalah halaman yang berfungsi untuk membuat report tentang barang produksi yang telah dibuat setiap harinya, dan report yang dibuat berdasarkan tanggal yang dipilih. 


\section{SIMPULAN}

Sistem yang dibangun ini dapat membantu pada bagian gudang perusahaan dalam melakukan pengecekan stok dikarenakan dalam penyimpanan informasi stok menggunakan database yang memungkinkan penyimpanan data secara sistematis, rapih, dan dapat dilihat. Sistem yang dibangun ini mengatur secara sistematis data-data yang diinput dari barang masuk, produksi, barang keluar. Menghitung secara otomatis data yang sudah ada dan meminimalkan kesalahan pada perhitungan. Pada proses reporting sistem dapat dengan mudah membantu dalam pengolahan data yang menjadikan prosesnya lebih cepat dari proses reporting yang berjalan sebelumnya.

Penelitian selanjutnya dapat dilakukan untuk mengetahui persepsi pengguna ini terhadap aplikasi yang dihasilkan (Rembulan, 2019).

\section{DAFTAR PUSTAKA}

Heizer, J., Render, B. dan Munson, C. (2017) Operations Management: Sustainability and Supply Chain Management. 12 ed. New York: Pearson Education.

Indrajani, S. M. (2011) Pengantar dan Sistem Basis Data. Jakarta: PT. Elex Media Komputindo.

Karo-Karo, G., Lois, C. dan Nurprihatin, F. (2017) "Usulan Perencanaan dan Pengendalian Baku Boks Panel dengan Menggunakan Metode Material Requirements Planning (MRP)," in Prosiding Seminar Nasional Akuntansi dan Bisnis. Bandung: Universitas Widyatama, hal. 923-933.

Kotler, P. dan Keller, K. L. (2016) Marketing Management. 15 ed. London: Pearson Education Limited. doi: 10.1080/08911760903022556.

Nurprihatin, F. et al. (2019) "A Distribution Strategy Using A Two-step Optimization to Maximize Blood Services Considering Stochastic Travel Times," in IOP Conference Series: Materials Science and Engineering. IOP Publishing Ltd. doi: 10.1088/1757-899X/650/1/012043.

Nurprihatin, F., Yulita, N. E. dan Caesaron, D. (2017) "Usulan Pengurangan Pemborosan pada Proses Penjahitan Menggunakan Metode Lean Six Sigma," in Prosiding Seminar Nasional Akuntansi dan Bisnis. Bandung: Universitas
Widyatama, hal. 809-818.

Pressman, R. S. dan Maxim, B. R. (2015) Software Engineering A Practitioner's Approach. 8 ed. New York: McGraw-Hill Education.

Regina, T., Luin, J. A. dan Rembulan, G. D. (2020) "Mengurangi Keterlambatan Waktu Produksi Menggunakan Line Balancing pada Sektor Konstruksi Jalan Tol," in Prosiding Seminar Nasional Riset dan Teknologi. Jakarta: Universitas Indraprasta PGRI, hal. 258-263.

Rembulan, G. D. (2018) "Faktor-faktor yang Memengaruhi Getok Tular pada Usaha Restoran Waralaba di Jakarta," Jurnal Pengabdian dan Kewirausahaan, 2(1), hal. 17-28.

Rembulan, G. D. (2019) "Pengembangan Industri Kecil dan Menengah Tiwul Instan sebagai Alternatif Pendukung Ketahanan Pangan dalam Perspektif Konsumen," Industria: Jurnal Teknologi dan Manajemen Agroindustri, 8(2), hal. 87-94. doi: 10.21776/ub.industria.2019.008.02.2.

Rembulan, G. D. et al. (2020) "Optimalisasi Panjang Jaringan Pipa Air Bersih di DKI Jakarta Menggunakan Minimum Spanning Tree," Jurnal Intech, 6(1), hal. 75-87. doi: 10.30656/intech.v6i1.2164.

Rowena, J., Wilujeng, F. R. dan Rembulan, G. D. (2020) "Pengaruh Kualitas Layanan dalam Menciptakan Kepuasan Publik di Kantor Pelayanan Publik, Jakarta Utara," Journal of Industrial Engineering and Management Systems, 13(1), hal. 27-34. doi: 10.30813/jiems.v13i1.2083.

Tannady, H. et al. (2019) "Process Improvement to Reduce Waste in the Biggest Instant Noodle Manufacturing Company," Journal of Applied Engineering Science, 17(2), hal. 203-212. doi: 10.5937/jaes1718951.

Wilujeng, F. R. et al. (2019) "Meningkatkan Kepuasan Pelanggan pada Dua Bisnis ECommerce Terbesar di Indonesia dengan Menggunakan Analisis Servqual dan IPA," in Prosiding Seminar Nasional Sains dan Teknologi. Jakarta: Fakultas Teknik Universitas Muhammadiyah Jakarta, hal. 1-9.

Wilujeng, F. R. dan Rembulan, G. D. (2019) "Perancangan Model Kualitas Pelayanan Puskesmas dengan Metode Importance 
Performance Analysis (IPA) dan Quality Function Deployment (QFD)," Jurnal Intech, 5(2), hal. 43-50. doi: 10.30656/intech.v5i2.1675.

Wilujeng, F. R., Rembulan, G. D. dan Regina, T. (2019) "Pengukuran Kualitas Layanan dengan Metode Service Quality pada Puskesmas Jakarta Utara," in Prosiding Seminar Nasional Teknik Industri. Lhokseumawe: Universitas Malikussaleh. 